\title{
Air pollution exposure during pregnancy and reduced birth size: a prospective birth cohort study in Valencia, Spain
}

\author{
Ferran Ballester ${ }^{1,2,3^{*}}$, Marisa Estarlich², Carmen Iñiguez ${ }^{1,2}$, Sabrina Llop ${ }^{2,1}$, Rosa Ramón ${ }^{2,4}$, Ana Esplugues ${ }^{1,2}$,
} Marina Lacasaña ${ }^{5,2}$, Marisa Rebagliato ${ }^{6,2}$

\begin{abstract}
Background: Maternal exposure to air pollution has been related to fetal growth in a number of recent scientific studies. The objective of this study was to assess the association between exposure to air pollution during pregnancy and anthropometric measures at birth in a cohort in Valencia, Spain.

Methods: Seven hundred and eighty-five pregnant women and their singleton newborns participated in the study. Exposure to ambient nitrogen dioxide $\left(\mathrm{NO}_{2}\right)$ was estimated by means of land use regression. $\mathrm{NO}_{2}$ spatial estimations were adjusted to correspond to relevant pregnancy periods (whole pregnancy and trimesters) for each woman. Outcome variables were birth weight, length, and head circumference ( $\mathrm{HC})$, along with being small for gestational age (SGA). The association between exposure to residential outdoor $\mathrm{NO}_{2}$ and outcomes was assessed controlling for potential confounders and examining the shape of the relationship using generalized additive models (GAM).

Results: For continuous anthropometric measures, GAM indicated a change in slope at $\mathrm{NO}_{2}$ concentrations of around $40 \mathrm{\mu g} / \mathrm{m}^{3}$. $\mathrm{NO}_{2}$ exposure $>40 \mathrm{\mu g} / \mathrm{m}^{3}$ during the first trimester was associated with a change in birth length of $-0.27 \mathrm{~cm}(95 \% \mathrm{Cl}:-0.51$ to -0.03$)$ and with a change in birth weight of -40.3 grams (-96.3 to 15.6); the same exposure throughout the whole pregnancy was associated with a change in birth $\mathrm{HC}$ of $-0.17 \mathrm{~cm}(-0.34$ to -0.003$)$. The shape of the relation was seen to be roughly linear for the risk of being SGA. A $10 \mu \mathrm{g} / \mathrm{m}^{3}$ increase in $\mathrm{NO}_{2}$ during the second trimester was associated with being SGA-weight, odds ratio (OR): 1.37 (1.01-1.85). For SGAlength the estimate for the same comparison was OR: 1.42 (0.89-2.25).

Conclusions: Prenatal exposure to traffic-related air pollution may reduce fetal growth. Findings from this study provide further evidence of the need for developing strategies to reduce air pollution in order to prevent risks to fetal health and development.
\end{abstract}

\section{Background}

In recent years a growing body of epidemiological research has focused on the potential impact of prenatal exposure to air pollution on birth outcomes. Several outcomes have been related to exposure to air pollution during pregnancy, including low birth weight, reduced birth size, and intrauterine growth retardation [1-4]. Moreover, reduction in fetal growth has been associated

\footnotetext{
* Correspondence: ballester_fer@gva.es
${ }^{1}$ Center for Public Health Research (CSISP), Conselleria de Sanitat, Avda

* Correspondence: ballester_fer@gva.es
${ }^{1}$ Center for Public Health Research (CSISP), Conselleria de Sanitat, Avda Catalunya 21, 46020, Valencia, Spain
}

with poor neurological development as well as with an increased risk for chronic diseases later in life $[5,6]$.

A cohort study is the design of choice for evaluating the impact of air pollution on fetal growth as pregnancy is a process in which the relationship between a given type of exposure and an associated effect may be observed in a limited period of time [7]. Some of the studies carried out on this topic have included large populations using birth data from health care registries [8-10] whereas other cohort studies had smaller samples, but more detailed, primary data [11-13]. Authors of recent methodological reviews $[7,14-16]$ agree that 
new prospective studies should allow for adequate assessment of air pollution exposure, consider different time windows of exposure, and collect sufficient information on confounding variables.

Nitrogen dioxide $\left(\mathrm{NO}_{2}\right)$ is the air pollutant most frequently used as a surrogate for traffic-related pollution in prospective studies, both in adults and in children $[17,18]$. This is due to the fact that outdoor $\mathrm{NO}_{2}$ levels correlate well with pollutants generated by traffic, they can be easily measured using passive samplers, and they are routinely measured by air quality networks, which allows for correction for seasonality.

The INMA study (Spanish Children's Health and Environment) is a prospective multi-centre pregnancy and birth cohort study that seeks to evaluate the role of the environment on fetal development and children's health in the general population in Spain [19]. The objective of this report is to assess the association between residential exposure to outdoor $\mathrm{NO}_{2}$ during pregnancy and anthropometric measures at birth.

\section{Methods}

\section{Study design and population}

The present study was based on data from the INMA cohort in Valencia. Between November 2003 and June 2005, 855 pregnant women attending the prenatal population-based screening program at the reference hospital were included in the study. Thirty-five of these women had a spontaneous abortion or fetal death, 33 withdrew from the study or were lost to follow up, and 787 delivered a live, singleton infant. Exposure to outdoor $\mathrm{NO}_{2}$ was assessed for 785 of the 787 mother-child pairs in the study, thus making up the final study population. Deliveries took place between May 2004 and February 2006. The study area covered the home addresses of all participants. Approximately $10 \%$ lived in a typically urban zone (city of Valencia), 50\% lived in the metropolitan zone, $35 \%$ in a semi-urban zone, and the rest in a typically rural zone. The study area covers $1372 \mathrm{~km}^{2}$ including 34 municipalities and has a reference population of almost 300,000 inhabitants with a broad sociodemographic and environmental heterogeneity. The study protocol was approved by the Ethics Committee of the reference hospital and informed consent was obtained from every participating woman. The mothers' recruitment and follow up procedures have been previously reported [19].

\section{Birth outcome assessment}

Outcome variables were birth weight (in grams), birth length and head circumference (in centimetres). Birth weight was measured by the midwife that attended the birth, whereas birth length and head circumference were measured by a nurse when the newborn arrived in the hospital ward within the first twelve hours of life. The three measures were standardized for gestational age and sex using the residuals method [20]. An early ultrasound of the crown-rump length was also available and used for gestational dating when the difference with the last menstrual period was equal to or greater than 7 days. This happened in $11.9 \%$ of the cases. We defined small for gestational age (SGA) as a birth weight or length below the $10^{\text {th }}$ percentile according to standard percentile charts for sex and gestational age in the Spanish population [21]. We did not classify SGA in terms of head circumference because our measurement procedure was different from that used in the published charts. Of all the births, $6.4 \%$ were classified as preterm births (i.e. gestational age $<37$ weeks) in the studied cohort.

\section{Assessment of air pollution exposure}

A procedure was designed to assess individual exposure to $\mathrm{NO}_{2}$ as a marker of outdoor air pollution considering both spatial and temporal variations on exposure. Ambient $\mathrm{NO}_{2}$ concentrations for 93 sampling points covering the study area were obtained using radial symmetry passive samplers (Radiello ${ }^{\circledR}$, Fondazione Salvatore Maugeri, Padua/Italy) which remained exposed for four sampling periods of 7 days each. The campaigns took place in April, June, and November 2004 and February 2005. The passive samplers were distributed over the area according to geometrical criteria, taking into account the expected pollution gradients and the expected number of births (Figure 1). For obtaining estimates of the $\mathrm{NO}_{2}$ spatial distribution in the study area, a two step approach was used. First, universal kriging was used to predict $\mathrm{NO}_{2}$ levels at unmonitored sites, i.e. the women's residences. Then, geographical information system (GIS) data (traffic, i.e. vehicle density and distance to a main road, land use, and altitude) were used to improve predictions with the aid of land use regression (LUR).

In addition, in order to take into account temporal variations in exposure, we used daily information from seven stations of the monitoring network within $5 \mathrm{~km}$ or less of the study area to adjust $\mathrm{NO}_{2}$ spatial estimations to correspond with the pregnancy period for each woman. Thus, the $\mathrm{NO}_{2}$ spatial estimation for each woman's residence was multiplied by the ratio between the $\mathrm{NO}_{2}$ monitoring network average during the pregnancy period of that particular woman divided by the $\mathrm{NO}_{2}$ monitoring network average for the entire study period. In order to explore critical exposure windows, an air pollution exposure indicator for each trimester of pregnancy was constructed using the same procedure as that utilized for the entire pregnancy. Address changes were taken into consideration when they accounted for a relevant fraction of each exposure window $(>2 / 9)$. The 


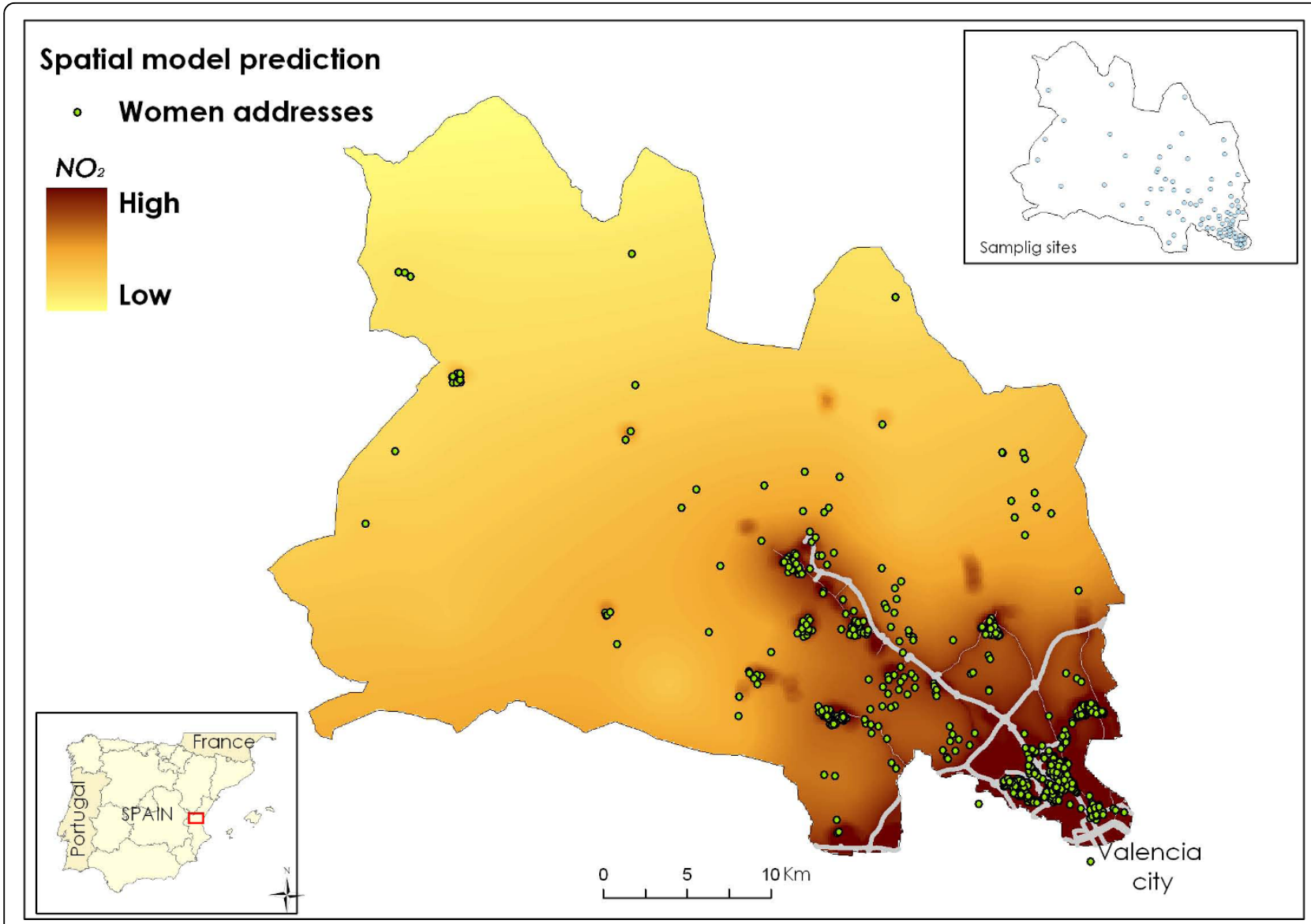

Figure 1 Spatial distribution of the $\mathrm{NO}_{2}$ levels in the study area and addresses of the women in the cohort.

methodology and results for assignment of personal air pollution exposure have been described elsewhere [22].

\section{Covariates and potential confounders}

The mothers completed a detailed questionnaire about socio-demographic characteristics, environmental exposures, and life style variables twice during their pregnancy (weeks 10-13 and 28-32). The questionnaires were administered during personal interviews by previously trained interviewers. Potential confounders included maternal variables (see Additional file 1), infant's sex, paternal height, and season of delivery. Body mass index (BMI) and gestational weight gain were further classified following the Institute of Medicine guidelines [23]. Socio-economic status (SES) was classified using an adaptation of the British SES classification. Environmental tobacco smoke exposure was assessed as both passive exposure at home and global exposure.

\section{Statistical Methods}

We first performed bivariate analysis to determine parental and pregnancy characteristics associated with birth outcomes. We also examined individual $\mathrm{NO}_{2}$ levels and maternal and pregnancy characteristics. Association between exposure to residential outdoor $\mathrm{NO}_{2}$ and anthropometric measures was assessed by means of linear regression for continuous variables and logistic regression for SGA. In order to avoid excessive influence of extreme values, robust methods were applied. For continuous variables, we checked for the shape of the relation using graphical smoothing techniques. The height of both parents showed a linear relation and was therefore included as a continuous variable in the models. The rest of the continuous variables were categorized to account for non-linear associations. Covariates were retained in the final model if they were related to the outcome based on likelihood ratio (LR) tests with a $p$ value of $<0.10$ or if they changed effect estimates for the exposure of interest by $>=10 \%$ when excluded from the model. The mother's age was included in all models in spite of its statistical significance. Zone of residence was not included in the multivariate analyses because it was highly correlated with $\mathrm{NO}_{2}$ levels. To assess the shape of the relationship between measures at birth and $\mathrm{NO}_{2}$ levels, we used adjusted GAM models to evaluate the linearity of the relation between $\mathrm{NO}_{2}$ levels and the reproductive 
outcomes, comparing models with $\mathrm{NO}_{2}$ levels in a linear and non-linear manner (a cubic smoothing spline with 2, 3 , and 4 degrees of freedom) by means of graphical examination and an LR test $(\mathrm{p}<0.05)$.

\section{Results}

Characteristics of the newborns, the mothers and their pregnancy, and the fathers' height in relation to size measures and SGA are described in Additional file 1. In brief, older mothers, mothers who had higher pre-pregnancy weight and/or BMI, who were taller, of higher social class, non-smokers, and of Latin American origin had infants with a higher birth weight and a lower proportion of SGA (in weight) babies. Primiparous mothers, those with low weight gain, those with only primary school education, and those who still smoked at week 12 had infants with a lower birth weight and a higher proportion of SGA (in weight) babies. Boys weighed more than girls. Similar patterns were found for birth length and head circumference adjusted for gestational age, and for SGA (in length) except that there were no differences by country of origin, and in the case of length, no differences by either social class or education were observed. Finally, taller fathers had bigger babies and a lower proportion of SGA babies.

The spatial distribution of $\mathrm{NO}_{2}$ levels throughout the study area showed a gradient from the urban zone to the rural one with the two motorways crossing the area playing an important role (Figure 1). The mean residential outdoor $\mathrm{NO}_{2}$ level corresponding to the 785 pregnancy periods was $36.9 \mu \mathrm{g} / \mathrm{m}^{3}$ (Table 1 ). For $43.2 \%$ of the women, the outdoor $\mathrm{NO}_{2}$ levels at their residences during the pregnancy period were above $40 \mu \mathrm{g} / \mathrm{m} 3$, the World Health Organization guideline for annual $\mathrm{NO}_{2}$ concentration [24]. Individual $\mathrm{NO}_{2}$ levels for each trimester correlated well with $\mathrm{NO}_{2}$ levels for the whole pregnancy, and moderately between themselves (Table 1).

\section{Air pollution exposure and anthropometric measures}

Unadjusted analysis considering the variables in their continuous form showed a negative relationship between individual exposures to ambient $\mathrm{NO}_{2}$ and anthropometric measures at birth (Table 2). This relation was statistically significant for first trimester exposure and for both birth length and head circumference, as well as for second trimester exposure and head circumference. After adjustment for covariates and potential confounders, the same temporal pattern persisted (Table 2). Although 95\% confidence intervals yielded results that do not reject the null hypothesis, birth head circumference and $\mathrm{NO}_{2}$ exposure in the first trimester were marginally associated. Specifically, an increase in $10 \mu \mathrm{g} / \mathrm{m}^{3}$ in $\mathrm{NO}_{2}$ levels during the first trimester of pregnancy was associated with a decrease in head circumference by $-0.07 \mathrm{~cm}$ (95\% CI: -0.14 to 0.005$)$.

When the shape of the relation between $\mathrm{NO}_{2}$ exposure and anthropometric measures was assessed, a nonlinear relationship was observed. In most cases in the multivariate analysis, the best fit was obtained when $\mathrm{NO}_{2}$ was introduced as a cubic smoothing spline with 3 or 4 degrees of freedom (Table 2). Graphic examination of the relation between $\mathrm{NO}_{2}$ exposure during the first trimester and birth weight and length, and between $\mathrm{NO}_{2}$ exposure during the second trimester and head circumference suggested a change in slope around $40 \mu \mathrm{g} /$ $\mathrm{m}^{3}$ (Figure 2). For this reason, the association between $\mathrm{NO}_{2}$ exposure and weight, length, and head circumference at birth was also analyzed considering $\mathrm{NO}_{2}$ as a categorical variable, i.e. $>40 \mu \mathrm{g} / \mathrm{m}^{3}$ versus $\leq 40 \mu \mathrm{g} / \mathrm{m}^{3}$ (Table 3). Results of the multivariate analysis indicated that $\mathrm{NO}_{2}$ exposure above $40 \mu \mathrm{g} / \mathrm{m}^{3}$ during the first trimester was associated with a reduction in birth length of $-0.27 \mathrm{~cm}(95 \% \mathrm{CI}-0.51$ to -0.03$)$. Birth weight was just marginally associated with $\mathrm{NO}_{2}$ exposure; i.e. a reduction of -40.3 grams in birth weight (95\%CI: -96.3 to 15.6) for the same comparison. Also a significant reduction in head circumference was found for exposures above $40 \mu \mathrm{g} / \mathrm{m}^{3}$ throughout the entire pregnancy.

\section{Analysis of the relationship with small for gestational age (SGA)}

In the bivariate analysis, although all the odds ratios (OR) were higher than 1 , no significant association was found for either of the two measures of SGA and

Table 1 Descriptive statistics of the estimates of individual exposure to ambient $\mathrm{NO}_{2}$ during the different pregnancy periods.

\begin{tabular}{|c|c|c|c|c|c|c|c|}
\hline \multirow[t]{2}{*}{ Pregnancy period } & \multirow[t]{2}{*}{ Mean $\left(\mu \mathrm{g} / \mathrm{m}^{3}\right)$} & \multicolumn{3}{|c|}{ Percentiles $\left(\mu \mathrm{g} / \mathrm{m}^{3}\right)$} & \multicolumn{3}{|c|}{ Pearson's correlation $(r)$ between periods } \\
\hline & & 25 & 50 & 75 & First trimester & Second trimester & Third trimester \\
\hline First trimester & 37.9 & 28.2 & 38.1 & 48.5 & & & \\
\hline Second trimester & 35.9 & 26.5 & 35.2 & 44.2 & $0.69^{*}$ & & \\
\hline Third trimester & 37.0 & 27.3 & 37.0 & 46.1 & $0.34^{*}$ & $0.65^{*}$ & \\
\hline Whole pregnancy & 36.9 & 29.4 & 37.9 & 45.6 & $0.80^{*}$ & $0.92^{*}$ & $0.83^{*}$ \\
\hline
\end{tabular}


Table 2 Association between individual exposure to ambient $\mathrm{NO}_{2}$ in different time periods during pregnancy and anthropometric measures at birth.*

\begin{tabular}{|c|c|c|c|c|c|c|c|c|c|}
\hline \multirow[b]{2}{*}{$\mathrm{NO}_{2}$ exposure period } & \multicolumn{3}{|c|}{$\begin{array}{c}\text { Birth weight (in g) } \\
(\mathrm{n}: 785)\end{array}$} & \multicolumn{3}{|c|}{$\begin{array}{c}\text { Birth length (in cm })^{\mathrm{a}} \\
(\mathrm{n}: 784)\end{array}$} & \multicolumn{3}{|c|}{$\begin{array}{c}\text { Birth head circumference (in cm })^{a} \\
(\mathrm{n}: 782)\end{array}$} \\
\hline & $\beta$ & $(95 \% \mathrm{Cl})$ & Linearity $(\mathrm{df})^{\mathrm{b}}$ & $\beta$ & $(95 \% \mathrm{Cl})$ & Linearity $(\mathrm{df})^{\mathrm{b}}$ & $\beta$ & $(95 \% \mathrm{Cl})$ & Linearity $(\mathrm{df})^{\mathrm{b}}$ \\
\hline \multicolumn{10}{|l|}{ Unadjusted } \\
\hline First trimester & -3.564 & $(-23.698 ; 16.570)$ & $\mathrm{L}$ & -0.092 & $(-0.177 ;-0.008)$ & $\mathrm{NL}(4)$ & -0.069 & $(-0.133 ;-0.004)$ & $\mathrm{L}$ \\
\hline Second trimester & -4.464 & $(-25.175 ; 16.248)$ & $\mathrm{NL}(3)$ & -0.050 & $(-0.137 ; 0.037)$ & $\mathrm{NL}(2)$ & -0.071 & $(-0.137 ;-0.004)$ & L \\
\hline Third trimester & -5.740 & $(-26.553 ; 15.072)$ & L & -0.010 & $(-0.096 ; 0.077)$ & $\mathrm{NL}(4)$ & -0.017 & $(-0.084 ; 0.049)$ & $\mathrm{L}$ \\
\hline Whole pregnancy & -5.792 & $(-30.065 ; 18.481)$ & $\mathrm{NL}(3)$ & -0.063 & $(-0.165 ; 0.038)$ & L & -0.074 & $(-0.152 ; 0.003)$ & $\mathrm{L}$ \\
\hline \multicolumn{10}{|l|}{ Adjusted $^{c}$} \\
\hline First trimester & -12.782 & $(-34.537 ; 8.972)$ & $\mathrm{NL}(3)$ & -0.066 & $(-0.149 ; 0.017)$ & $\mathrm{NL}(4)$ & -0.066 & $(-0.137 ; 0.005)$ & $\mathrm{L}$ \\
\hline Second trimester & -9.961 & $(-32.594 ; 12.671)$ & $\mathrm{NL}(4)$ & -0.040 & $(-0.125 ; 0.044)$ & $\mathrm{NL}(3)$ & -0.060 & $(-0.133 ; 0.014)$ & $\mathrm{NL}(3)$ \\
\hline Third trimester & -4.294 & $(-25.923 ; 17.335)$ & $L$ & -0.005 & $(-0.089 ; 0.079)$ & $\mathrm{NL}(2)$ & -0.028 & $(-0.099 ; 0.042)$ & $\mathrm{L}$ \\
\hline Whole pregnancy & -9.729 & $(-33.218 ; 13.760)$ & $\mathrm{L}$ & -0.047 & $(-0.146 ; 0.052)$ & $\mathrm{NL}(2)$ & -0.058 & $(-0.134 ; 0.018)$ & $\mathrm{NL}(3)$ \\
\hline
\end{tabular}

* Estimates are expressed as the change in birth anthropometric measures for a $10 \mu \mathrm{g} / \mathrm{m}^{3}$ increase in the mean $\mathrm{NO}_{2}$ levels at each woman's residence during the corresponding period. Unadjusted and adjusted models.

a Standardized for gestational age.

b Shape of the relationship after contrast between model with $\mathrm{NO}_{2}$ in non-linear vs. linear form; L: linear; NL: non-linear (and degrees of freedom of the selected model).

c Adjusted for:

-Birth weight = maternal age, maternal pre-pregnancy weight, maternal height, paternal height, gestational weight gain, parity, maternal education, smoking during pregnancy, country of origin, sex of the infant, and season of last menstrual period.

-Birth length = maternal age, maternal height, gestational weight gain, parity, maternal education, smoking during pregnancy, working status in the first trimester, country of origin, and sex of the infant.

-Birth head circumference: maternal age, maternal pre-pregnancy weight, maternal height, gestational weight gain, parity, maternal education, smoking during pregnancy, country of origin, sex of the infant, and season of last menstrual period.

Table 3 Association between individual exposure to ambient $\mathrm{NO}_{2}>40 \mu \mathrm{g} / \mathrm{m}^{3}$ in different time periods during pregnancy and anthropometric measures at birth.*

\begin{tabular}{|c|c|c|c|c|c|c|}
\hline \multirow[b]{2}{*}{$\mathrm{NO}_{2}$ exposure period } & \multicolumn{2}{|c|}{$\begin{array}{c}\text { Birth weight (in g) }{ }^{\mathrm{a}} \\
(\mathrm{n}: 785)\end{array}$} & \multicolumn{2}{|c|}{$\begin{array}{l}\text { Birth length (in } \mathrm{cm})^{\mathrm{a}} \\
(\mathrm{n}: 784)\end{array}$} & \multicolumn{2}{|c|}{$\begin{array}{l}\text { Birth head circumference (in } \mathrm{cm})^{\mathrm{a}} \\
(\mathrm{n}: 782)\end{array}$} \\
\hline & $\beta$ & $(95 \% \mathrm{Cl})$ & $\beta$ & $(95 \% \mathrm{Cl})$ & $\beta$ & $(95 \% \mathrm{Cl})$ \\
\hline \multicolumn{7}{|c|}{ Unadjusted } \\
\hline First trimester & -24.309 & $(-78.256 ; 29.638)$ & -0.300 & $(-0.526 ;-0.075)$ & -0.104 & $(-0.276 ; 0.069)$ \\
\hline Second trimester & -9.648 & $(-65.156 ; 45.860)$ & -0.100 & $(-0.333 ; 0.133)$ & -0.173 & $(-0.352 ; 0.005)$ \\
\hline Third trimester & 28.325 & $(-26.475 ; 83.126)$ & 0.150 & $(-0.079 ; 0.379)$ & 0.051 & $(-0.123 ; 0.226)$ \\
\hline Whole pregnancy & -16.912 & $(-71.233 ; 37.410)$ & -0.170 & $(-0.398 ; 0.058)$ & -0.152 & $(-0.326 ; 0.022)$ \\
\hline \multicolumn{7}{|c|}{ Adjusted $^{b}$} \\
\hline First trimester & -40.349 & $(-96.267 ; 15.568)$ & -0.271 & $(-0.514 ;-0.028)$ & -0.074 & $(-0.257 ; 0.108)$ \\
\hline Second trimester & -37.546 & $(-96.231 ; 21.140)$ & -0.190 & $(-0.447 ; 0.066)$ & -0.177 & $(-0.368 ; 0.014)$ \\
\hline Third trimester & 26.656 & $(-28.239 ; 81.551)$ & 0.077 & $(-0.161 ; 0.315)$ & 0.011 & $(-0.167 ; 0.190)$ \\
\hline Whole pregnancy & -33.292 & $(-84.874 ; 18.290)$ & -0.199 & $(-0.424 ; 0.027)$ & -0.171 & $(-0.339 ;-0.003)$ \\
\hline
\end{tabular}

*Estimates are expressed as the change in birth anthropometric measures comparing $\mathrm{NO}_{2}$ exposure levels $>40 \mu \mathrm{g} / \mathrm{m}^{3} \mathrm{vs}$. exposure levels $\leq 40 \mu \mathrm{g} / \mathrm{m}^{3}$ at each woman residence during the corresponding period. Unadjusted and adjusted models.

a Standardized for gestational age.

${ }^{b}$ Adjusted for:

-Birth weight: maternal age, maternal pre-pregnancy weight, maternal height, paternal height, gestational weight gain, parity, maternal education, smoking during pregnancy, country of origin, sex of the infant, and season of last menstrual period.

-Birth length: maternal age, maternal height, gestational weight gain, parity, maternal working status in the first trimester, smoking during pregnancy, country of origin, sex of the infant, and season of last menstrual period.

-Birth head circumference: maternal age, maternal pre-pregnancy weight, maternal height, gestational weight gain, parity, maternal education, smoking during pregnancy, working status in the third trimester, sex of the infant, and season of last menstrual period. 


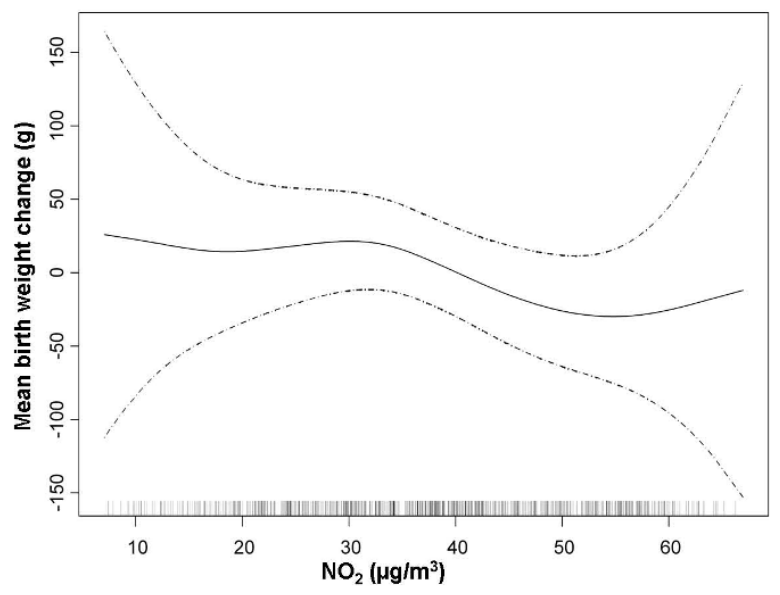

(B)

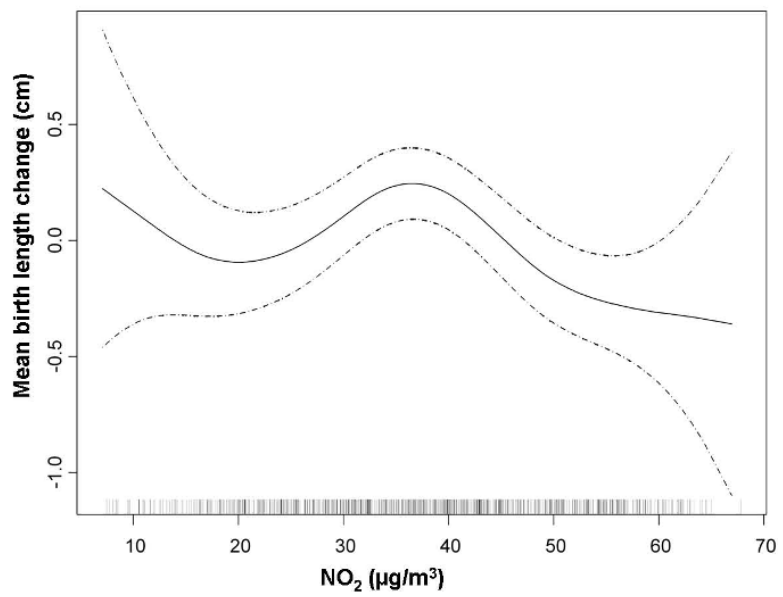

(C)

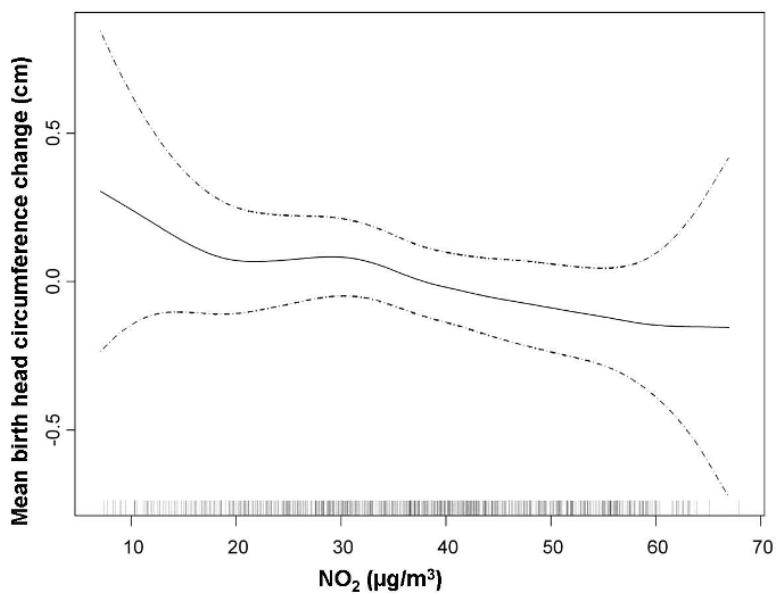

Figure 2 Relationship between individual $\mathrm{NO}_{2}$ exposure during the first trimester and anthropometric measures at birth. Graphical estimation of the association and 95\% confidence intervals for the non-linear model with lower AIC (degrees of freedom: $d f$ ). (A). Birth weight (gr) and $\mathrm{NO}_{2}$ exposure $(3 \mathrm{df}) \mathrm{B}$ ). Birth length $(\mathrm{cm})$ and $\mathrm{NO}_{2}$ exposure $(4 \mathrm{df})$. (C). Birth head circumference $(\mathrm{cm})$ and $\mathrm{NO}_{2}$ exposure $(4 \mathrm{df})$. Footnote for Figure 2(C): For birth head circumference the model with the best adjustment was the linear model. 
exposure to $\mathrm{NO}_{2}$ during pregnancy (Table 4). After adjustment for potential confounders, a clearer association emerged with the second trimester being the most relevant window of exposure. A $10 \mu \mathrm{g} / \mathrm{m}^{3}$ increase in $\mathrm{NO}_{2}$ during the second trimester was thus associated with the risk of SGA-weight, OR: 1.37 (95\%CI: 1.011.85). For SGA-length the association estimate for the same comparison was OR: 1.42 (95\%CI: 0.89-2.25). No significant improvement in the model was obtained with non-linear models for SGA (Figure 3); therefore, we have only included the results for the relationship with $\mathrm{NO}_{2}$ exposure as a continuous variable (Table 4).

\section{Discussion}

Results from this mother and child cohort living in a large, heterogeneous area in Valencia, Spain, suggest an association between maternal exposure to outdoor air pollution and birth outcomes. The odds of being SGAweight increased by $37 \%$ when ambient $\mathrm{NO}_{2}$ levels increased $10 \mu \mathrm{g} / \mathrm{m}^{3}$ during the second trimester of pregnancy. For anthropometric measures in continuous form, an association with air pollution appeared for women living in zones with ambient $\mathrm{NO}_{2}$ levels above $40 \mu \mathrm{g} / \mathrm{m}^{3}$. The first and second trimesters seem to be the relevant window of exposure.

Results for the different air pollutants varied in the different studies. Besides particulate matter (PM) [either of diameter $<10 \mu \mathrm{m}-\mathrm{PM}_{10^{-}}$or $<2.5 \mu \mathrm{m}-\mathrm{PM}_{2.5^{-}}$] and carbon monoxide (CO), $\mathrm{NO}_{2}$ appears as one of the pollutants more frequently associated with birth outcomes. In a previous review [2] we identified six articles reporting associations between $\mathrm{NO}_{\mathrm{x}}$ or $\mathrm{NO}_{2}$ with either birth weight, low birth weight (LBW, measured as birth weight $<2500 \mathrm{~g}$ ), or SGA. The three articles that included nitrogen oxides $\left(\mathrm{NO}_{\mathrm{x}}\right)$ were ecological in design and used data from central monitors. None of them found an association between $\mathrm{NO}_{\mathrm{x}}$ and birth weight. For $\mathrm{NO}_{2}$, results from the literature reviewed suggested some association with birth weight, but were still not conclusive $[8,25,26]$. In recent years a considerable number of articles have been published in this field. We have identified 12 articles studying the association of $\mathrm{NO}_{2}$ exposure with birth weight that were published after our previous review (Additional file 2) [10,12,27-36]. Of the four studies analyzing birth weight, an association was found in three of them: Bell et al. in Massachusetts and Connecticut (USA) [10], Mannes et al. in Sydney (Australia) [32], and Gouveia and cols in Brazil [29], but no relationship was observed in the Children's Health Study [31]. Interestingly, all but one of the articles [36] studying SGA found an association with $\mathrm{NO}_{2}$; in the study in question, however, $\mathrm{NO}_{2}$ was the only pollutant studied to be associated with head circumference. As an example, in their study in Vancouver, Brauer et al. [35] estimated residential exposures to air pollution and the risk of SGA. Of the seven air pollutants studied, the association with $\mathrm{NO}_{2}$ was the most robust. On the other hand, only three studies found an association between $\mathrm{LBW}$ and $\mathrm{NO}_{2}[10,28,35]$. This discrepancy may be due to the fact that the number of cases of SGA is greater than that of LBW term babies, which gives the study more statistical power. Moreover,

Table 4 Association between individual exposure to ambient $\mathrm{NO}_{2}$ in different time periods during pregnancy and Small for Gestational Age (SGA).*

\begin{tabular}{|c|c|c|c|c|c|c|}
\hline \multirow[b]{2}{*}{$\mathrm{NO}_{2}$ exposure period } & \multicolumn{3}{|c|}{$\begin{array}{l}\text { SGA - weight } \\
\text { (n: 785) }\end{array}$} & \multicolumn{3}{|c|}{$\begin{array}{l}\text { SGA - length } \\
(\mathrm{n}: 784)\end{array}$} \\
\hline & OR & $(95 \% \mathrm{Cl})$ & Linearity (df) ${ }^{a}$ & $\mathrm{OR}$ & $(95 \% \mathrm{Cl})$ & Linearity (df) $^{a}$ \\
\hline \multicolumn{7}{|c|}{ Unadjusted } \\
\hline First trimester & 1.013 & $(0.992 ; 1.035)$ & $\mathrm{L}$ & 1.001 & $(0.968 ; 1.035)$ & L \\
\hline Second trimester & 1.013 & $(0.992 ; 1.034)$ & L & 1.006 & $(0.972 ; 1.041)$ & $L$ \\
\hline Third trimester & 1.004 & $(0.983 ; 1.026)$ & $\mathrm{L}$ & 1.013 & $(0.979 ; 1.049)$ & $L$ \\
\hline Whole pregnancy & 1.014 & $(0.988 ; 1.040)$ & $\mathrm{L}$ & 1.010 & $(0.970 ; 1.052)$ & $L$ \\
\hline \multicolumn{7}{|c|}{ Adjusted $^{\mathrm{b}}$} \\
\hline First trimester & 1.182 & $(0.894 ; 1.563)$ & $\mathrm{L}$ & 1.137 & $(0.741 ; 1.744)$ & L \\
\hline Second trimester & 1.369 & $(1.013 ; 1.849)$ & $\mathrm{L}$ & 1.416 & $(0.890 ; 2.254)$ & $\mathrm{L}$ \\
\hline Third trimester & 1.186 & $(0.906 ; 1.552)$ & $\mathrm{L}$ & 1.103 & $(0.750 ; 1.623)$ & $\mathrm{L}$ \\
\hline Whole pregnancy & 1.281 & $(0.942 ; 1.743)$ & $\mathrm{L}$ & 1.230 & $(0.778 ; 1.945)$ & L \\
\hline
\end{tabular}

*Estimates are expressed as the change in odds for SGA (birth weight) and SGA (birth length) for a $10 \mu \mathrm{g} / \mathrm{m}^{3}$ increase in the mean $\mathrm{NO}_{2}$ levels at each woman's residence during the corresponding period. Unadjusted and adjusted models.

${ }^{a}$ Shape of the relationship after contrast between model with $\mathrm{NO}_{2}$ in non-linear vs. linear form; L: linear; NL: non-linear (and degrees of freedom of the selected model).

${ }^{b}$ Adjusted for:

-SGA in weight: maternal age, maternal pre-pregnancy weight, paternal height, gestational weight gain, parity, maternal education, country of origin, smoking during pregnancy, and season of last menstrual period.

-SGA in length: maternal age, maternal pre-pregnancy weight, maternal education, parity, smoking during pregnancy, gestational weight gain, country of origin alcohol consumption during pregnancy, and season of last menstrual period. 
(A)

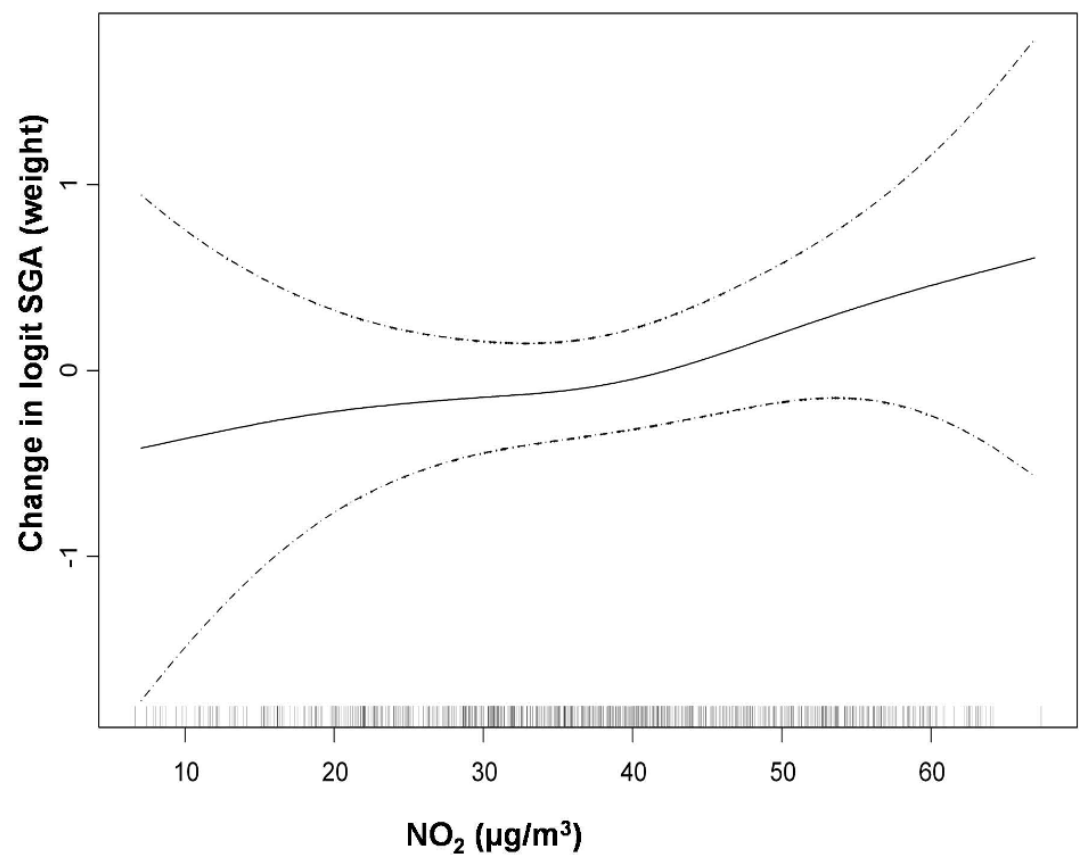

(B)

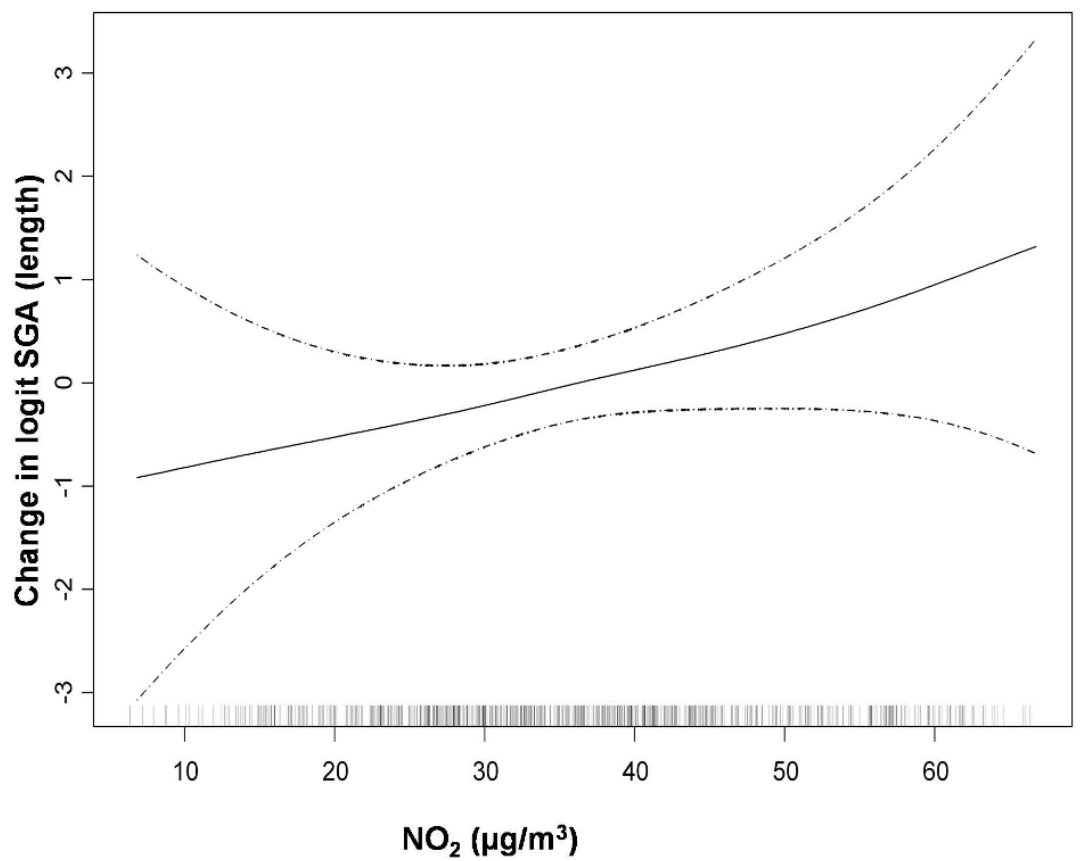

Figure 3 Relationship between individual $\mathrm{NO}_{2}$ exposure during the second trimester and small for gestational age, in birth weight and in birth length in a multivariate analysis. Graphical estimation of the association and $95 \%$ confidence intervals for the non-linear model with lower AIC (degrees of freedom: df). A). Logit of small for gestational age in birth weight and $\mathrm{NO}_{2}$ exposure (2 df). Footnote for Figure 3(A): For SGA (in birth weight) the model with the best adjustment was the linear model. (B). Logit of small for gestational age in birth length and $\mathrm{NO}_{2}$ exposure (2 df). Footnote for Figure 3(B): For SGA (in birth length) the model with the best adjustment was the linear model. 
the use of SGA, calculated for each week of gestation, enables the effect of gestational length to be more effectively controlled than LBW, which is estimated simply by selecting births that take place after a certain period of gestation (i.e. between weeks 37-44).

Few studies have examined the relation between air pollution exposure during pregnancy and other anthropometric indicators such as birth length or head circumference (HC). Studies of two cohorts of pregnant women in Poland and in New York described a relationship between prenatal exposure to airborne polycyclic aromatic hydrocarbons (PAH) and fetal growth [37]. Regarding prenatal $\mathrm{NO}_{2}$ exposure and birth length or $\mathrm{HC}$, a birth register-based study assessed birth length and $\mathrm{HC}$ among 26,617 term births in Brisbane, Australia [36]. An IQR range increase in $\mathrm{NO}_{2}\left(11.1 \mu \mathrm{g} / \mathrm{m}^{3}\right)$, but not in other pollutants, during the third trimester was associated with a reduction in crown-heel length: $-0.15 \mathrm{~cm}(95 \% \mathrm{CI}:-0.25$ to -0.05). Moreover, in the French Eden cohort [38] a reduction of $-0.31 \mathrm{~cm}$ in $\mathrm{HC}$ at birth was found when comparing $\mathrm{NO}_{2}$ exposure in the highest tertile $(>31.4 \mu \mathrm{g} /$ $\mathrm{m}^{3}$ ) to that in the lowest tertile. Our results are consistent with the findings of these two studies.

Up to now a clear window of susceptibility for growth retardation has not been identified. In our study we found that exposure during the first trimester is most closely related to a decrease in birth weight and length. In the case of SGA (both, in weight and in length) however, the strongest relationship was found with exposure in the second trimester. Regarding reduced $\mathrm{HC}$, when exposure was evaluated above vs. below $40 \mu \mathrm{g} / \mathrm{m}^{3}$, exposure throughout the pregnancy was the most clearly related. This may indicate that exposure during the entire pregnancy plays the most important role for reduction in the growth of the infant head.

Very few studies have completely assessed the shape of the relationship between air pollution exposure and reproductive outcomes. Instead, most have analyzed the relation using air pollution variables in the continuous form or comparing only two levels. Some have attempted to examine the shape using tertiles or quartiles and observed an increased risk of LBW at higher quartiles [12,28]. Regarding $\mathrm{NO}_{2}$ exposure and birth weight, only $\mathrm{Ha}$ et al. [25] examined this relationship using GAM models, as did we in the present study. In the former study, although the authors considered the relationship to be relatively linear, a change in the slope may be observed in the figures, with a higher negative gradient after $\mathrm{NO}_{2}$ values of around $32 \mathrm{ppb}(60$ $\left.\mu \mathrm{g} / \mathrm{m}^{3}\right)$. In our study, we found some indication of a reduction in birth length starting at a threshold of approximately $40 \mu \mathrm{g} / \mathrm{m}^{3}$. For HC and the risk of SGA we found a monotonic relationship with air pollution exposure.

The biological mechanisms by which air pollutants may affect fetal growth are still unclear. There is some evidence that $\mathrm{NO}_{2}$ alters fetal growth and thus may play a causal role. $\mathrm{NO}_{2}$ is a potent oxidant and increased lipid peroxidation in the maternal and/or fetal compartment has been found in preterm births [39]. Tabacova et al. investigated the relationship between exposure to nitrogen-oxidizing species and pregnancy complications in an area in Bulgaria highly polluted by oxidized nitrogen compounds [40]. Methemoglobin, a biomarker of individual exposure, was determined, and glutathione balance and lipid peroxide levels were used as measures of oxidant/antioxidant status. A high percentage of women suffered from pregnancy complications, the most common being anaemia (67\%), threatened abortion/premature labour (33\%), and signs of preeclampsia (23\%). Methemoglobin was significantly elevated in all three conditions, in comparison with normal pregnancies. Reduced:total glutathione, an indicator of maternal antioxidant reserves, decreased, whereas cell-damaging lipid peroxide levels increased. More recently, Mohoroviz found similar results for methemoglobin in a polluted area of Croatia [41]. These results suggest that maternal exposure to environmental oxidants can increase the risk of pregnancy complications through stimulation of methemoglobin formation, which may lead to hypoxia and hypoxemia in pregnant women and has an important influence on maternal health as well as on placental and fetal development.

Our study has several limitations. The number of women participating in the study is small compared with that in other studies. Subsequently, the power of the study is fairly low and the estimates have wide confidence intervals. In addition, we had no information available on other important pollutants such as $\mathrm{PM}_{10}, \mathrm{PM}_{2.5}$, sulphur dioxide $\left(\mathrm{SO}_{2}\right)$, and $\mathrm{CO}$, for which some associations with fetal growth have been described in other studies. Consequently, we cannot affirm that $\mathrm{NO}_{2}$ is the air pollutant definitively associated with birth measurements. Due to the colinearity between pollutants, $\mathrm{NO}_{2}$ may simply be a proxy for other toxins. Still, $\mathrm{NO}_{2}$ has been shown to be a marker of air pollution from road traffic [42] and could be a reasonable marker of ultrafine particulates or PAH from this source. Unfortunately, we did not have information on indoor levels of air pollutants. However we did have information on environmental tobacco smoke exposure, an important source of indoor air pollution, and we controlled for this.

Notwithstanding the aforementioned weaknesses, our study has several important strengths. In this prospective study we followed a pregnant cohort from early pregnancy and assessed exposure, health outcomes, and covariates in great detail. In addition, the statistical approach using GAM models allows us to examine the shape of the relationship while the use of robust methods permits the minimization of the influence of 
extreme values. Moreover, we developed a protocol combining measurements from $\mathrm{NO}_{2}$ passive samplers, kriging, and LUR in order to obtain estimates of individual exposure to ambient $\mathrm{NO}_{2}$ for each woman. We also performed four different campaigns to assess the stability over time of the spatial $\mathrm{NO}_{2}$ distribution in the study area, as recommended by Ritz and Wilhelm [15]. Our method allowed us to address local heterogeneity in order to assign an individual estimate of the exposure, a problem that has been reported to affect other studies $[15,30]$. Lastly, our study had access to detailed information about each woman's residence throughout pregnancy, including changes of location and address.

\section{Conclusions}

Findings from this mother and birth cohort study in Valencia, Spain, suggest that prenatal exposure to outdoor air pollution, measured as $\mathrm{NO}_{2}$, affects the anthropometric development of the fetus, reducing its length and head circumference and increasing the risk of having a small for gestational age (in weight) baby.

We found an association between exposure to levels of $\mathrm{NO}_{2}$ above $40 \mu \mathrm{g} / \mathrm{m}^{3}$ during the first trimester of pregnancy and a reduction in birth weight. This association was only marginal for birth length.

For head circumference $(\mathrm{HC})$ reduction and the risk of SGA, a monotonic relationship with air pollution exposure was observed. The relevant period of exposure for the risk of SGA was the second trimester. Exposure throughout the pregnancy played the most important role in decreased $\mathrm{HC}$.

Compared with other recent studies, $\mathrm{NO}_{2}$ levels in the study area occupy an intermediate position; therefore, the results are not due to extreme exposure conditions. Taking into account the relationship between fetal growth reduction and child development and health, strategies should be developed to reduce air pollution in order to prevent these risks.

\section{Additional file 1: Characteristics of pregnant women and their} association with birth outcomes in the INMA-Valencia cohort, 20032006. Table with the distribution of the outcome variables among the categories of the covariates at study.

Click here for file

[http://www.biomedcentral.com/content/supplementary/1476-069X-9-6S1.DOC]

Additional file 2: Results from studies assessing $\mathrm{NO}_{2}$ effect on birth weight published between 2003-2008. Table summarizing the design and main results of studies published between 2003-2008 on air pollution exposure during pregnancy that included $\mathrm{NO} 2$ as air pollution indicator and birth weight.

Click here for file

[ http://www.biomedcentral.com/content/supplementary/1476-069X-9-6S2.DOC]

\section{Abbreviations}

BMI: Body mass index; BSP: Black smoke particles; Cl: confidence interval; CO: carbon monoxide; GAM: generalized additive models; GIS: geographical information system; HC: head circumference; INMA: Spanish Children's Health and Environment study; IQR: Interquartile range; LBW: low birth weight (measured as birth weight $<2500 \mathrm{~g}$ ); LR: likelihood ratio; LUR: land use regression; $\mathrm{NO}_{2}$ : nitrogen dioxide; $\mathrm{NO}_{x}$ : nitrogen oxides; OR: odds ratio; PAH: polycyclic aromatic hydrocarbons; PM: particulate matter; $\mathrm{PM}_{10}$ : particulate matter of diameter $<10 \mu \mathrm{m} ; \mathrm{PM}_{2.5}$ : particulate matter of diameter $<2.5 \mu \mathrm{m}$; ppb: parts per billion; PR: prevalence ratio; SES: socio-economic status; SGA: small for gestational age; $\mathrm{SO}_{2}$ : sulphur dioxide.

\section{Acknowledgements}

The authors give special thanks to the families in the study as well as to the professionals that gave their support to this study.

Funding: Instituto de Salud Carlos III (G03/176), FIS-FEDER 03/1615, 04/1509, 04/1112 and 06/1213, and the Conselleria de Sanitat Generalitat Valenciana; all in Spain.

\section{Author details}

${ }^{1}$ Center for Public Health Research (CSISP), Conselleria de Sanitat, Avda Catalunya 21, 46020, Valencia, Spain. ${ }^{2}$ Spanish Consortium for Research on Epidemiology and Public Health (CIBERESP), Doctor Aiguader 88, 08003, Barcelona, Spain. ${ }^{3}$ School of Nursing, Universitat de València, C Jaume Roig $s / n$ 46010, Valencia, Spain. ${ }^{4}$ General Directorate of Public Health. Conselleria de Sanitat, Avda Catalunya 21, 46020, Valencia, Spain. ${ }^{5}$ Andalusian School of Public Health (EASP), Campus de la Cartuja s/n, Granada, Spain. ${ }^{6}$ Department of Public Health, Rey Juan Carlos University, 28922, Alcorcón, Madrid, Spain.

\section{Authors' contributions}

Authors contributed to the article as follows: FB conceived the study, supervised the data collection and data analysis, and prepared the manuscript. ME contributed to data collection, conducted the data analysis of the association of interest, and helped with manuscript preparation. Cl prepared the outcome variables, developed the land use regression analysis, assisted with data analysis, and helped with data interpretation and manuscript preparation. SL, AE, RR, ML, and MR contributed to data collection, provided critical revision of the manuscript, and helped with data interpretation and manuscript preparation. All authors have read and given final approval of the version to be published.

\section{Competing interests}

The authors declare that they have no competing interests.

Received: 23 October 2009

Accepted: 29 January 2010 Published: 29 January 2010

\section{References}

1. Sram RJ, Binkova B, Dejmek, Bobak M: Ambient air pollution and pregnancy outcomes: a review of the literature. Environ Health Perspect 2005, 113:375-382.

2. Lacasana $M$, Esplugues $A$, Ballester F: Exposure to ambient air pollution and prenatal and early childhood health effects. Eur J Epidemiol 2005, 20:183-199.

3. Maisonet M, Correa A, Misra D, Jaakkola JJ: A review of the literature on the effects of ambient air pollution on fetal growth. Environ Res 2004, 95:106-115.

4. Glinianaia SV, Rankin J, Bell R, Pless-Mulloli T, Howel D: Particulate air pollution and fetal health: a systematic review of the epidemiologic evidence. Epidemiology 2004, 15:36-45.

5. Richards M, Hardy R, Kuh D, Wadsworth ME: Birth weight, postnatal growth and cognitive function in a national UK birth cohort. Int J Epidemiol 2002, 31:342-348.

6. Barker DJ: The origins of the developmental origins theory. I Intern Med 2007, 261:412-417.

7. Woodruff TJ, Parker JD, Darrow LA, Slama R, Bell ML, Choi H, Glinianaia S, Hoggatt K, Karr CJ, Lobdell DT, Wilhelm M: Methodological issues in 
studies of air pollution and reproductive health. Environ Res 2009, 109:311-320.

8. Wilhelm M, Ritz B: Residential proximity to traffic and adverse birth outcomes in Los Angeles County, California, 1994-1996. Environ Health Perspect 2003, 111:207-216.

9. Parker JD, Woodruff TJ, Basu R, Schoendorf KC: Air pollution and birth weight among term infants in California. Pediatrics 2005, 115:121-128.

10. Bell ML, Ebisu K, Belanger K: Ambient air pollution and low birth weight in Connecticut and Massachusetts. Environ Health Perspect 2007, 115:1118-1124.

11. Perera FP, Rauh V, Tsai WY, Kinney P, Camann D, Barr D, Bernert T, Garfinkel R, Tu YH, Diaz D, Dietrich J, Whyatt RM: Effects of transplacental exposure to environmental pollutants on birth outcomes in a multiethnic population. Environ Health Perspect 2003, 111:201-206.

12. Slama R, Morgenstern V, Cyrys J, Zutavern A, Herbarth O, Wichmann HE, Heinrich J: Traffic-related atmospheric pollutants levels during pregnancy and offspring's term birth weight: a study relying on a land-use regression exposure model. Environ Health Perspect 2007, 115:1283-1292.

13. Choi H, Rauh V, Garfinkel R, Perera FP: Prenatal exposure to airborne polycyclic aromatic hydrocarbons and risk of intrauterine growth restriction. Environ Health Perspect 2008, 116:658-665.

14. Basu R, Woodruff TJ, Parker JD, Saulnier L, Schoendorf KC: Comparing exposure metrics in the relationship between $\mathrm{PM}_{2.5}$ and birth weight in California. J Expo Anal Environ Epidemiol 2004, 14:391-396.

15. Ritz B, Wilhelm M: Ambient air pollution and adverse birth outcomes: methodologic issues in an emerging field. Basic Clin Pharmacol Toxicol 2008, 102:182-190

16. Slama R, Darrow L, Parker J, Woodruff TJ, Strickland M, Nieuwenhuijsen M, Glinianaia S, Hoggatt KJ, Kannan S, Hurley F, Kalinka J, Srám R, Brauer M, Wilhelm M, Heinrich J, Ritz B: Meeting report: atmospheric pollution and human reproduction. Environ Health Perspect 2008, 116:791-798.

17. Jerrett M, Shankardass K, Berhane K, Gauderman WJ, Kunzli N, Avol E, Gilliland F, Lurmann F, Molitor JN, Molitor JT, Thomas DC, Peters J, McConnell R: Traffic-related air pollution and asthma onset in children: a prospective cohort study with individual exposure measurement. Environ Health Perspect 2008, 116:1433-1438.

18. Brunekreef B: Health effects of air pollution observed in cohort studies in Europe. J Expo Sci Environ Epidemiol 2007, 17(Suppl 2):S61-S65.

19. Ribas-Fito N, Ramon R, Ballester F, Grimalt J, Marco A, Olea N, Posada M, Rebagliato M, Tardon A, Torrent M, Sunyer J: Child health and the environment: the INMA Spanish Study. Paediatr Perinat Epidemiol 2006, 20:403-410.

20. Lindsay RS, Hanson RL, Bennett PH, Knowler WC: Secular trends in birth weight, BMI, and diabetes in the offspring of diabetic mothers. Diabetes Care 2000, 23:1249-1254

21. Carrascosa A, Yeste D, Copil A, Almar J, Salcedo S, Gussinye M: [Anthropometric growth patterns of preterm and full-term newborns (24-42 weeks' gestational age) at the Hospital Materno-Infantil Vall d'Hebron (Barcelona)(1997-2002]. An Pediatr (Barc) 2004, 60:406-416.

22. Iñiguez $C$, Ballester $F$, Estarlich $M$, Fernandez-Patier $R$, Aguirre-Alfaro $A$, Esplugues A, INMA Study group Valencia: Estimation of personal $\mathrm{NO}_{2}$ exposure in a cohort of pregnant women. Sci Total Environ 2009, 15:6093-6099.

23. Abrams B, Altman SL, Pickett KE: Pregnancy weight gain: still controversial. Am J Clin Nutr 2000, 71(Suppl 5):S1233-S1241.

24. World Health Organization: . WHO air quality guidelines for particulate matter, ozone, nitrogen dioxide and sulfur dioxide. Global update 2005 Geneva, Switzerland: WHO 2006, 15

25. Ha EH, Hong YC, Lee BE, Woo BH, Schwartz J, Christiani DC: Is air pollution a risk factor for low birth weight in Seoul? Epidemiology 2001, 12:643-648.

26. Maroziene L, Grazuleviciene R: Maternal exposure to low-level air pollution and pregnancy outcomes: a population-based study. Environ Health 2002, 1:6

27. Liu S, Krewski D, Shi Y, Burnett RT: Association between gaseous ambient air pollutants and adverse pregnancy outcomes in Vancouver, Canada. Environ Health Perspect 2003, 111:1773-1778.

28. Lee BE, Ha EH, Park HS, Kim YJ, Hong YC, Kim H, Lee JT: Exposure to air pollution during different gestational phases contributes to risks of low birth weight. Hum Reprod 2003, 18:638-643.
29. Gouveia N, Bremner SA, Novaes HM: Association between ambient air pollution and birth weight in Sao Paulo, Brazil. J Epidemiol Community Health 2004, 58:11-17.

30. Wilhelm M, Ritz B: Local variations in $\mathrm{CO}$ and particulate air pollution and adverse birth outcomes in Los Angeles County, California, USA. Environ Health Perspect 2005, 113:1212-1221.

31. Salam MT, Millstein J, Li YF, Margolis HG, Gilliland FD: Birth outcomes and prenatal exposure to ozone, carbon monoxide, and particulate matter: results from the Children's Health Study. Environ Health Perspect 2005, 113:1638-1644

32. Mannes T, Jalaludin B, Morgan G, Lincoln D, Sheppeard V, Corbett S: Impact of ambient air pollution on birth weight in Sydney, Australia. Occup Environ Med 2005, 62:524-530.

33. Liu S, Krewski D, Shi Y, Chen Y, Burnett RT: Association between maternal exposure to ambient air pollutants during pregnancy and fetal growth restriction. J Expo Sci Environ Epidemiol 2007, 17:426-432.

34. Hansen C, Neller A, Williams G, Simpson R: Maternal exposure to low levels of ambient air pollution and preterm birth in Brisbane, Australia. BJOG 2006, 113:935-941.

35. Brauer M, Lencar C, Tamburic L, Koehoorn M, Demers P, Karr C: A cohort study of traffic-related air pollution impacts on birth outcomes. Environ Health Perspect 2008, 116:680-686.

36. Hansen C, Neller A, Williams G, Simpson R: Low levels of ambient air pollution during pregnancy and fetal growth among term neonates in Brisbane, Australia. Environ Res 2007, 103:383-389.

37. Choi H, Jedrychowski W, Spengler J, Camann DE, Whyatt RM, Rauh V, Tsai WY, Perera FP: International studies of prenatal exposure to polycyclic aromatic hydrocarbons and fetal growth. Environ Health Perspect 2006, 114:1744-1750.

38. Slama RS, Sinno-Teller S, Thiébaugeorges O, Goua V, Forhan A, Ducot B, Annesi-Maesano I, Heinrich J, Schweitzer M, Magnin G, Bouyer J, Kaminski M, Charles MA, Eden Study Group: Relation between atmospheric pollutants and head circumference in utero and at birth: a cohort study relying on ultrasound imaging during pregnancy. Epidemiology 2006, 17:S129-S130.

39. Moison RM, Palinckx JJ, Roest M, Houdkamp E, Berger HM: Induction of lipid peroxidation of pulmonary surfactant by plasma of preterm babies. Lancet 1993, 341:79-82.

40. Tabacova S, Balabaeva L, Little RE: Maternal exposure to exogenous nitrogen compounds and complications of pregnancy. Arch Environ Health 1997, 52:341-347.

41. Mohorovic $\mathrm{L}$ : The level of maternal methemoglobin during pregnancy in an air-polluted environment. Environ Health Perspect 2003, 111:1902-1905.

42. Clougherty JE, Wright RJ, Baxter LK, Levy Jl: Land use regression modeling of intra-urban residential variability in multiple traffic-related air pollutants. Environ Health 2008, 7:17.

doi:10.1186/1476-069X-9-6

Cite this article as: Ballester et al: Air pollution exposure during pregnancy and reduced birth size: a prospective birth cohort study in Valencia, Spain. Environmental Health 2010 9:6.

\section{Submit your next manuscript to BioMed Central and take full advantage of:}

- Convenient online submission

- Thorough peer review

- No space constraints or color figure charges

- Immediate publication on acceptance

- Inclusion in PubMed, CAS, Scopus and Google Scholar

- Research which is freely available for redistribution

Submit your manuscript at www biomedcentral.com/submit
Biomed Central 